\title{
BMJ Open Self-management and blood pressure control in China: a community-based multicentre cross-sectional study
}

\author{
Zhan Qu, ${ }^{\oplus 1}$ Monica Parry, ${ }^{\oplus 2}$ Fang Liu, ${ }^{1}$ Xiulin Wen, ${ }^{3}$ Jieqiong Li, ${ }^{3}$ Yanan Zhang, ${ }^{4}$ \\ Duolao Wang, ${ }^{5}$ Xiaomei $\mathrm{Li}^{1}$
}

To cite: Qu Z, Parry M, Liu F, et al. Self-management and blood pressure control in China: a community-based multicentre cross-sectional study. BMJ Open 2019;9:e025819. doi:10.1136/ bmjopen-2018-025819

- Prepublication history and additional material for this paper are available online. To view these files, please visit the journal online (http://dx.doi. org/10.1136/bmjopen-2018025819).

Received 2 August 2018 Revised 1 February 2019 Accepted 1 February 2019

Check for updates

(C) Author(s) (or their employer(s)) 2019. Re-use permitted under CC BY-NC. No commercial re-use. See rights and permissions. Published by BMJ.

${ }^{1}$ School of Nursing, Xi'an Jiaotong University, Health Science Center, Xi'an, Shaanxi, China

${ }^{2}$ Lawrence S. Bloomberg Faculty of Nursing, University of Toronto, Toronto, Ontario, Canada

${ }^{3}$ The First Affiliated Hospital of Xi'an Jiaotong University, Xi'an, Shaanxi, China

${ }^{4}$ School of Public Health, Xi'an Jiaotong University, Health

Science Center, Xi'an, Shaanxi, China

${ }^{5}$ Department of Clinical

Sciences, Liverpool School of Tropical Medicine, Liverpool, UK

Correspondence to

Xiaomei Li;

roselee8825@163.com

\section{ABSTRACT}

Objectives This study explored the relationship between self-management and blood pressure (BP) control in China. Design A cross-sectional study.

Setting Eight community health centres from four cities in the Northeast (Shenyang), Northwest (Xi'an), Southwest (Chengdu) and South (Changsha) of China.

Participants A total of 873 adults with hypertension, including 360 men and 513 women. Hypertension was defined as systolic BP $\geq 140 \mathrm{~mm} \mathrm{Hg}$ and/or diastolic BP $\geq 90 \mathrm{~mm} \mathrm{Hg}$.

Outcome measurements BP control was the primary outcome variable. This was categorised as good control if individuals with hypertension reduced their BP to $<140 / 90 \mathrm{~mm} \mathrm{Hg}$, otherwise, it was categorised as poor control. Secondary outcomes included self-management, defined as: (1) context or condition-specific factors or physical/social environments (eg, age, sex, marital status, education, personal income and health insurance) and (2) process or knowledge/beliefs, self-regulation skills/ abilities and social facilitation (eg, treatment, diet, exercise and risk factor management). Data were analysed using logistic regression models using SPSS V.20.

Results A total of $67.1 \%(n=586)$ participants had poor $\mathrm{BP}$ control. Limited outpatient care benefits in mainly rural residents (OR $2.26,95 \% \mathrm{Cl} 1.06$ to 4.81$)$ and longer disease duration (OR $1.03,95 \% \mathrm{Cl} 1.01$ to 1.04 ) were associated with poor BP control. Self-management practices reduced the odds of having poor $\mathrm{BP}$ control (OR $0.98,95 \% \mathrm{Cl} 0.97$ to 0.99 ).

Conclusions The individual and family self-management theory can serve as an effective theory for understanding the key contexts, processes and outcomes essential for $\mathrm{BP}$ control in China. Future research should evaluate the effect of a self-management intervention (eg, selfmonitoring, medication adherence, regular and routine doctor visits, and social supports) for BP control in China using a multisite cluster randomised controlled trial. Sex and gender difference, cost and patient-reported outcomes should also be examined.

\section{BACKGROUND}

The prevalence of hypertension has increased worldwide. ${ }^{1}$ It is the most significant risk factor of cardiovascular disease (CVD), accounting for nearly half of the cardiovascular morbidity and mortality in the

\section{Strengths and limitations of this study}

A strength is the use of the individual and family self-management theory to guide the study.

- A strength is incorporation of a sex-based analysis.

- A strength is an attempt to use a surrogate marker of gender in the interpretation of results (level of education, personal income and employment status).

- A limitation is the use of the self-management scale for patients with hypertension. It has not been widely used and requires further psychometric testing.

- As this is a cross-sectional study, results are limited by self-reported survey questions. Additionally, there could be other unobserved confounding factors we have neither considered nor controlled.

world..$^{2-5}$ In China, hypertension is a serious public health problem; it has increased almost $400 \%$ from 1980 to 2015 (from an estimated 59 million to 244.5 million ${ }^{6-8}$ and has accounted for over 2 million deaths or $24.6 \%$ of all-cause mortality. ${ }^{9}$ Hypertensive complications in China are similar to other countries, which include stroke, myocardial infarction, heart failure and chronic kidney disease. ${ }^{10}$ Stroke is the leading cause of death and disability in China with an annual mortality of 1.6 million $^{11}$; hypertension is the most important risk factor for stroke with the highest attributable risk at 34.6\%. ${ }^{11}$ Annual stroke healthcare expenditures are approximately $¥ 40$ billion (US $\$ 6.4$ billion), causing a huge burden to the Chinese economy. ${ }^{11}$ Domestic and international research studies have proved that adequate control of blood pressure (BP) reduces stroke, ${ }^{12} \mathrm{CVD}^{13}$ and burden of disease, ${ }^{14}$ and significantly improves health-related quality of life (HRQOL). ${ }^{1617}$

The Chinese government launched the Chinese Basic Public Health Service Program in 2009; this provides a package of care that includes hypertension and diabetes screening and management in various community 
healthcare facilities. In 2013, the 17-country Prospective Urban Rural Epidemiology study reported hypertension awareness of $46.5 \%$, treatment of $87.5 \%$ and control of $32.5 \% .^{2}$ In 2017, the China Patient-Centred Evaluative Assessment of Cardiac Events study of 1.7 million individuals with hypertension suggested the prevalence of hypertension in China was $37.2 \%$, with an awareness of $36 \%$, treatment of $22.9 \%$ and control of only $5.7 \% .^{8}$ These results suggest that current governmental packages of care are insufficient to address the burden of hypertension in China. ${ }^{18}$

Successful self-management strategies for individuals can result in effective control of BP. ${ }^{19}{ }^{20}$ Many studies of hypertension self-management have improved BP outcomes in the Western societies, ${ }^{1521} 22$ however, the evidence for hypertension self-management is absent in the Chinese population. A recent systematic review identified only two quasi-experimental studies focusing on hypertension self-management in a population of American Chinese ${ }^{23}$; much of the evidence was derived from a single urban site so is not representative of individuals living in community settings. ${ }^{2425}$

The individual and family self-management theory (IFSMT) suggests a dynamic model of self-management consisting of: (1) condition-specific factors and physical/social environments (context), (2) knowledge and beliefs, self-regulation skills and abilities, and social facilitation (process), and (3) cost, health status and HRQOL (outcomes). ${ }^{26}$ Self-regulation includes the processes used to change behaviour, such as setting goals, self-monitoring, reflective thinking, planning/participating in specific behaviours, management of responses and self-evaluation. ${ }^{26}$ Approaches to managing hypertension using the IFSMT within the Chronic Care Model ${ }^{27}{ }^{28}$ suggest individuals use self-regulation skills and abilities ${ }^{19} 2930$ and work in partnership with healthcare providers to improve outcomes. $^{31}$

Sex and gender differences have been gaining attention in the development and management of hypertension. ${ }^{32-34}$ Women are twice as likely to have uncontrolled BP after menopause, ${ }^{32}$ have a higher prevalence of obesity $^{35}$ and are less likely to engage in physical activities $^{36}$ compared with men. Although the treatment benefit of antihypertensive agents may not differ between men and women, ${ }^{37}$ women with hypertension are less likely to achieve recommended BP targets, ${ }^{34} 38$ even with significantly higher use of antihypertensive medications. ${ }^{34}$ Sex and gender are distinct concepts often used interchangeably in the literature, both are important to hypertension prevalence, awareness and management. ${ }^{223539}$ Sex represents the biological characteristics of being male or female and gender represents the social norms and expectations ascribed to men and women. ${ }^{40}$ Gender differences in women's self-management practices are affected by broader social, environmental and community factors described as gender roles, gender identity, gender relationships and institutionalised gender. ${ }^{42}$
The aim of this study is to describe context and process variables within the IFSMT that impact BP control (outcomes) in men and women in China. This includes exploring both sex and gender aspects to self-management and BP control in Chinese adults living in the community.

\section{METHODS}

\section{Study design and settings}

Using a cross-sectional study design, individuals with hypertension were recruited from eight community healthcare centres in the Northeast (Shenyang city), Northwest (Xi'an city), Southwest (Chengdu city) and South (Changsha city) of China from April 2015 to January 2016. Four geographical areas were chosen in an attempt to recruit a representative sample of individuals with hypertension in China.

\section{Participants}

Recruitment was conducted in four steps. First, forty national model community health centres (CHCs) accredited between 2011 and 2013 were purposely selected from the four cities in China. ${ }^{43-45}$ These centres provide national standardised medical care to more than 100000 individuals within a district in each of the four cities. Second, two community healthcare centres were randomly selected in each city from the forty national model community centres using a random number table for study participation. Third, 1048 individuals (131 from each CHC) who had been screened and diagnosed with hypertension within the past 6 months were randomly recruited from electronic healthcare information systems. Fourth, individuals were contacted to determine their interest in participating in a telephone interview to learn more about the study.

Individuals who met the following inclusion criteria were recruited to participate: age $\geq 18$ years, systolic BP (SBP) $\geq 140 \mathrm{~mm} \mathrm{Hg}$ and/or diastolic BP $($ DBP) $\geq 90 \mathrm{~mm}$ $\mathrm{Hg}$ or prescribed antihypertensive medication for at least 6 months and able to identify their hypertensive medications within their medication schedule, able to read and write the Chinese language, and able to provide written informed consent to participate in the study. Individuals were excluded if they were pregnant, had cancer or were identified as being cognitively impaired in the health record (<recommendeda cut-off score of 26 using the Montreal Cognitive Assessment Chinese version-Beijing version). ${ }^{46}$

Trained research assistants who followed standard operating procedures explained the purpose and confidentiality of the study to participants and informed consent was obtained prior to survey completion.

\section{Patient and public involvement}

Patients and the public were not involved in the design of this study. 


\section{Measurement}

The IFSMT guided data collection and measurement. ${ }^{26}$

\section{Context}

Demographic (age, sex, marital status, education, personal income and health insurance) data were collected by interview using investigator-developed questionnaires. Marital status was divided into two categories: married or single/divorced/widowed. Education was categorised as primary school or no formal education $(<6$ years of schooling), high school (6-12 years of schooling) or college or higher (>12 years of schooling). Personal income was divided into two categories: $\leq ¥ 1500$ (US\$225) or $>¥ 1500$ (US\$225) based on Chinese individual income tax rates. ${ }^{47}$ Health insurance was divided into four categories: Urban Employees' Medical Insurance (UEMI), Urban Residents' Medical Insurance (URMI), New Rural Cooperative Medical Scheme (NCMS) and uninsured.

Risk behaviours included smoking (smoker (current smokers who smoked more than one cigarette daily)) or non-smoker (smoked fewer than 6 months or never smoked)) and alcohol consumption (consumer or non-consumer (consumed less than one glass per month or never drank)). Family history of hypertension was defined as a blood relative such as mother, father, sister or brother with diagnosed hypertension (SBP $\geq 140$ $\mathrm{mm} \mathrm{Hg}$ and/or DBP $\geq 90$ ). Anthropometric measures included weight and height (body mass index (BMI)) and waist circumference (WC)). BMI was calculated as weight in kilograms divided by height in metres squared and classified into four levels according to the guidelines for prevention and control of overweight and obesity in Chinese adults: underweight $\left(<18.5 \mathrm{~kg} / \mathrm{m}^{2}\right)$, normal $\left(18.5-23.9 \mathrm{~kg} / \mathrm{m}^{2}\right)$, overweight $\left(24.0-27.9 \mathrm{~kg} / \mathrm{m}^{2}\right)$ and obese: $\left(\geq 28 \mathrm{~kg} / \mathrm{m}^{2}\right) .{ }^{4-50}$ WC was divided into two categories: obese (men $\geq 90 \mathrm{~cm}$, women $\geq 80$ ) and normal (men $<90 \mathrm{~cm}$, women $<80 \mathrm{~cm}$ ) according to the International Diabetes Federation ${ }^{51}$ and National Institute for Health and Care Excellence.$^{52}$ Comorbidities were self-reported and based on a physician's diagnosis.

\section{Process}

The self-management scale for individuals with hypertension ${ }^{53}$ used in this study was developed by the China Medical Foundation community chronic disease management research group. Split-half reliability of the scale was 0.976 and Cronbach's alpha ranged from 0.853 to 0.868 on each of the 5 subscales. The 5 subscales contained 21 Likert scale items addressing: treatment management, diet management, physical exercise management, lifestyle management and risk factor management. Subscale scores ranged from 1 to 5 and total scores ranged from 21 to 105 , with higher scores indicating higher self-management behaviours (online supplementary file). In this study, original subscale scores were converted to standard scores for comparisons.

\section{Outcomes}

Blood Pressure: BP control was defined as a good if individuals had an $\mathrm{SBP}<140 \mathrm{~mm} \mathrm{Hg}$ and $\mathrm{DBP}<90 \mathrm{~mm} \mathrm{Hg}$. BPs were taken by trained nurses using a mercury sphygmomanometer according to the criterion formulated by the Chinese Hypertension League/National Centre for Cardiovascular Disease. ${ }^{54}$ Two BP readings for each participant were obtained at $2 \mathrm{~min}$ intervals in a sitting position and then averaged for analysis.

\section{Bias}

This study is cross-sectional and results may be subject to a non-response bias. ${ }^{55}$ However, recruiting a large number of individuals with hypertension across four areas of China attempted to minimise this bias. As this is an observational study, results are limited by self-reported survey questions. Additionally, there could be other unobserved confounding factors we have neither considered nor controlled.

\section{Sample size}

The sample size was based on 15-30 subjects per predictor in the logistic regression model. ${ }^{56}$ Given there were 22 predictors, the final sample size was estimated at 660 . The final sample size was increased to a total of 792 participants to account for a $20 \%$ attrition ( $\mathrm{n}=106$ participants from each community healthcare centre).

\section{Data analysis}

All data were analysed using SPSS V.20. Univariate statistics (frequencies, percentages and means) were used to describe the contextual factors of the sample. Bivariate associations between context and process variables were assessed using $\mathrm{X}^{2}$ and $\mathrm{t}$-tests or Mann-Whitney $\mathrm{U}$ tests for non-normally distributed outcome variables.

Based on the IFSMT theory, a multivariable logistic regression model was used to examine the association between context (individual/family, condition specific), process (BP self-regulation skills and abilities (treatment management, diet management, physical exercise management, lifestyle management, risk factor management), CHC visits, hospitals visits) and outcomes (BP control). Preliminary steps included assessing for multicollinearity using the variance inflation factor. A hierarchical approach was used to build our final model, ${ }^{55}$ starting with model 1 , then cumulatively adding clusters (models 2 and 3 ) of variables.

In model 1, the non-modifiable context variables related to the individual/family (age, sex, marital status, education, employment, personal incomes and health insurance) were explored. In model 2, modifiable variables that were condition specific (BMI, WC, disease duration, comorbidities, family history, smoking and alcohol consumption) were added to model 1 . In model 3 , processes variables related to self-regulation skills and abilities (treatment management, diet management, physical exercise management, lifestyle management, risk factors management, $\mathrm{CHC}$ visits and hospitals visits) 


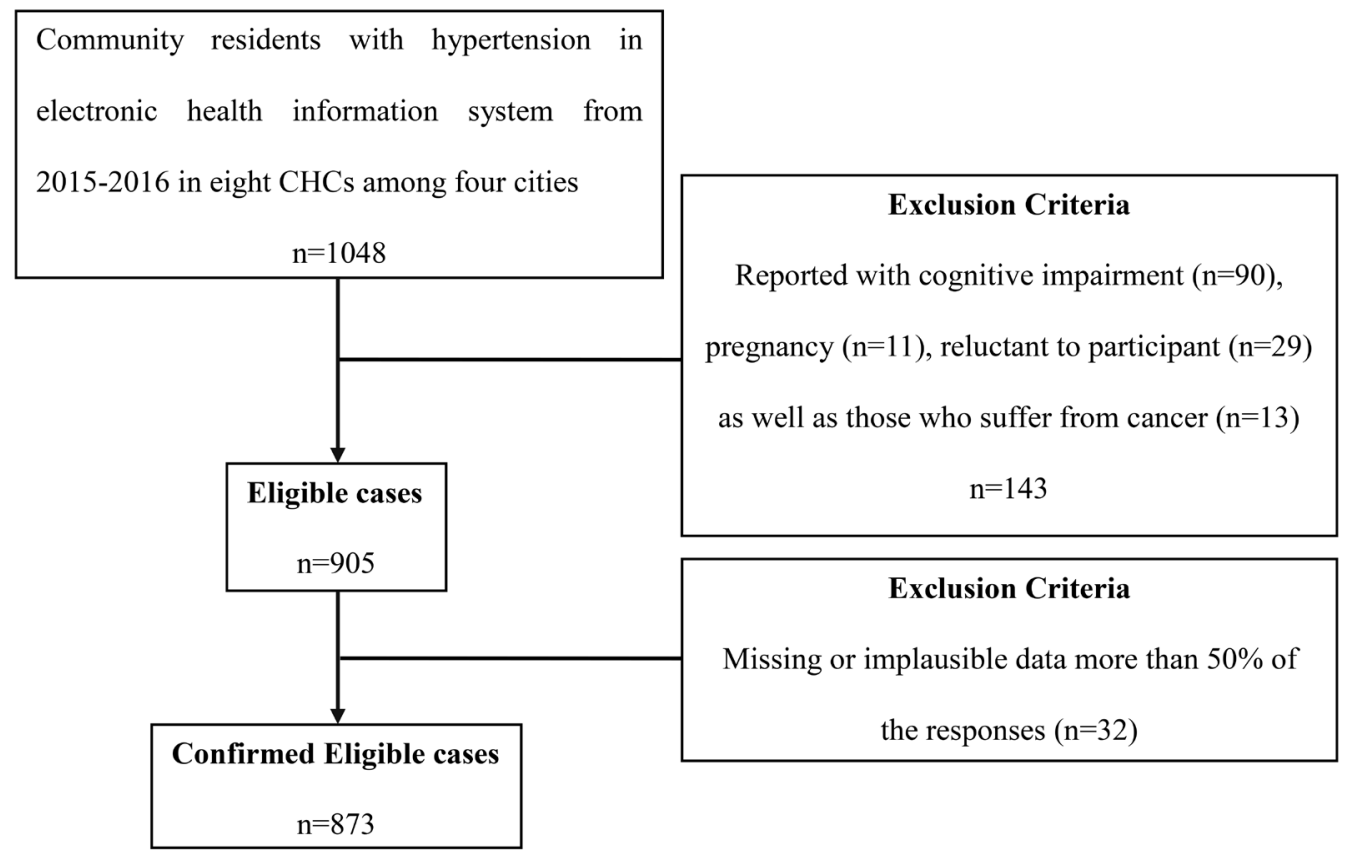

Figure 1 A flow chart of included and excluded cases. CHCs, community health centres.

were added to model 2. Nested models were compared using the likelihood ratio test (LRT). Clusters were kept in the model if they significantly contributed to model fit based on the LRT. A two-sided $\mathrm{p}<0.05$ was used to establish statistical significance.

\section{RESULTS}

Twenty-nine individuals refused to participate in the interview. Of those who participated, 114 individuals were excluded due to cognitive impairment $(n=90)$, pregnancy $(n=11)$ and cancer $(n=13)$. Of 905 eligible participants, 32 were excluded because of missing or implausible (more than $50 \%$ of the responses) data (figure 1). A total final sample of 873 individuals with hypertension (360 males, 513 females) consented to participate in the study.

\section{Context}

Demographic characteristics of participants are presented in table 1 . The mean age of participants was 65 years. Most of the samples were female $(n=513,58.8 \%)$, married $(\mathrm{n}=757,86.7 \%)$ and retired $(\mathrm{n}=596,68.3 \%)$. The majority of participants had health insurance $(n=839$, $96.1 \%), 10$ years disease duration and poor BP control $(\mathrm{n}=586,67.1 \%)$. Most had an abnormal BMI (underweight, overweight and obese) $(\mathrm{n}=569,65.1 \%)$ and $\mathrm{WC}$ $(\mathrm{n}=644,73.8 \%)$. Compared with men, more women were single/divorced/widowed, less likely to have graduated from college, were unemployed and had a lower personal income. Women were also more likely to be non-smokers and non-drinkers but had more comorbidities compared with men.

\section{Process}

Self-management process variables are reported in table 2. The lowest scores in self-management skills and abilities were in treatment management (eg, medication adherence, routine and regular doctors' visits, self-monitoring BP), physical exercise management, lifestyle management and diet management. Scores of risk factor management were highest. Compared with men, women were more likely to have higher total scores for self-management skills/abilities, diet management and risk factor management. Women also had more hospital visits compared with men.

\section{Outcomes}

Results of the logistic regressions analyses are depicted in table 3. All models had a good fit based on the Hosmer-Lemeshow test. In model 1, personal income and health insurance were significant for BP control. Participants with NCMS (medical scheme mainly for rural residents) compared with UEMI (medical insurance mainly for urban employees) increased the odds of poor BP control (OR 2.70, 95\% CI 1.28 to 5.67). When BMI, WC, smoking, drinking, family history, disease duration and comorbidities were added into model 2 , there was a slightly lower odds of NCMS compared with UEMI affecting poor BP control (OR 2.69, 95\% CI 1.27 to 5.69). A higher odd of having poor BP control was also observed with a longer duration of disease (OR 1.03, 95\% CI 1.01 to 1.04 ). A similar pattern was observed when treatment management, diet management, physical exercise management, lifestyle management, risk factor management, CHC visits and hospital visits were added to model 3. Self-management treatments reduced the odds of poor BP control in the final model (OR $0.98,95 \%$ CI 0.97 to 0.99 ). 
Table 1 Characteristics of community participants with hypertension

\begin{tabular}{|c|c|c|c|c|}
\hline & $\begin{array}{l}\text { Total } \\
(\mathrm{n}=873)\end{array}$ & $\begin{array}{l}\begin{array}{l}\text { Men } \\
(n=360)\end{array} \\
\end{array}$ & $\begin{array}{l}\text { Women } \\
(n=513)\end{array}$ & \\
\hline & $\begin{array}{l}\text { Mean (SD)/ } \\
\mathrm{n}(\%)\end{array}$ & $\begin{array}{l}\text { Mean (SD)/ } \\
\mathrm{n}(\%)\end{array}$ & $\begin{array}{l}\text { Mean (SD)/ } \\
\text { n (\%) }\end{array}$ & $P$ value \\
\hline Age (years) & 65 (9.5) & $65(9.9)$ & 66 (9.2) & 0.075 \\
\hline Marriage status & & & & $<0.001$ \\
\hline Married & $757(86.7)$ & $346(96.1)$ & $411(80.1)$ & \\
\hline Single/divorced/widowed & $116(13.3)$ & $14(3.9)$ & $102(19.9)$ & \\
\hline Education & & & & $<0.001$ \\
\hline Primary school or no & $183(21.0)$ & $53(14.7)$ & $130(25.3)$ & \\
\hline High school & $544(62.3)$ & $232(64.4)$ & $312(60.8)$ & \\
\hline College or higher & $146(16.7)$ & $75(20.8)$ & $71(13.8)$ & \\
\hline Employment & & & & $<0.001$ \\
\hline Employed & $145(16.6)$ & $91(25.3)$ & $54(10.5)$ & \\
\hline Unemployed & $132(15.1)$ & 44 (12.2) & $88(17.2)$ & \\
\hline Retired & $596(68.3)$ & $225(62.5)$ & $371(72.3)$ & \\
\hline Personal incomes & & & & $<0.001$ \\
\hline$\leq ¥ 1500$ (US\$225) & 307 (35.2) & $94(26.1)$ & $213(41.5)$ & \\
\hline$>¥ 1500$ (US\$225) & $566(64.8)$ & 266 (73.9) & $300(58.5)$ & \\
\hline Health insurance & & & & 0.170 \\
\hline UEMI & $636(72.9)$ & $271(75.3)$ & $365(71.2)$ & \\
\hline URMI & $103(11.8)$ & $32(8.9)$ & $71(13.8)$ & \\
\hline NCMS & $100(11.5)$ & $43(11.9)$ & $57(11.1)$ & \\
\hline Uninsured & $34(3.9)$ & $14(3.9)$ & $20(3.9)$ & \\
\hline \multicolumn{5}{|l|}{ BMI } \\
\hline Underweight & $10(1.1)$ & $2(0.6)$ & $8(1.6)$ & 0.377 \\
\hline Normal & $304(34.8)$ & $120(33.3)$ & $184(35.9)$ & \\
\hline Overweight & $412(47.2)$ & $178(49.4)$ & $234(45.6)$ & \\
\hline Obese & $147(16.8)$ & $60(16.7)$ & $87(17.0)$ & \\
\hline \multicolumn{5}{|l|}{ WC } \\
\hline Normal & 229 (26.2) & $144(40.0)$ & $85(16.6)$ & $<0.001$ \\
\hline Obese & $644(73.8)$ & $216(60.0)$ & $428(83.4)$ & \\
\hline Smoking status & & & & $<0.001$ \\
\hline Smoking & $239(27.4)$ & $216(60.0)$ & $23(4.5)$ & \\
\hline Non-smoking & $634(72.6)$ & $144(40.0)$ & $490(95.5)$ & \\
\hline Drinking status & & & & $<0.001$ \\
\hline Drinking & $196(22.5)$ & $176(48.9)$ & $20(3.9)$ & \\
\hline Non-drinking & $677(77.5)$ & $184(51.1)$ & $493(96.1)$ & \\
\hline Family history & & & & 0.944 \\
\hline Yes & $533(61.1)$ & $219(60.8)$ & $314(61.2)$ & \\
\hline No & $340(38.9)$ & $141(39.2)$ & $199(38.8)$ & \\
\hline Disease duration (years) & $10(9.0)$ & $9(7.9)$ & $10(9.7)$ & 0.079 \\
\hline \multicolumn{5}{|l|}{ Comorbidities } \\
\hline CAD & $195(22.3)$ & $75(20.8)$ & $120(23.4)$ & 0.370 \\
\hline Back/neck problem & $97(11.1)$ & $27(7.5)$ & $70(13.6)$ & 0.004 \\
\hline Stroke & $96(11.0)$ & $44(12.2)$ & $52(10.1)$ & 0.334 \\
\hline
\end{tabular}


Table 1 Continued

\begin{tabular}{|c|c|c|c|c|}
\hline & \multirow{2}{*}{$\begin{array}{l}\text { Total } \\
\text { (n=873) } \\
\text { Mean (SD)/ } \\
\mathrm{n}(\%)\end{array}$} & \multirow{2}{*}{$\begin{array}{l}\begin{array}{l}\text { Men } \\
(\mathrm{n}=360)\end{array} \\
\text { Mean (SD)/ } \\
\mathrm{n}(\%)\end{array}$} & \multirow{2}{*}{$\begin{array}{l}\text { Women } \\
(\mathrm{n}=513)\end{array}$} & \multirow[b]{2}{*}{$P$ value } \\
\hline & & & & \\
\hline Diabetes & $91(10.4)$ & $35(9.7)$ & $56(10.9)$ & 0.569 \\
\hline Arthritis & $61(7.0)$ & $18(5.0)$ & $43(8.4)$ & 0.049 \\
\hline COPD & $55(6.3)$ & $24(6.7)$ & $31(6.0)$ & 0.710 \\
\hline $\mathrm{Ml}$ & $17(1.9)$ & $10(2.8)$ & $7(1.4)$ & 0.141 \\
\hline Nephropathy & $11(1.3)$ & $7(1.9)$ & $4(0.8)$ & 0.132 \\
\hline Gastrointestinal disease & $10(1.1)$ & $5(1.4)$ & $5(1.0)$ & 0.574 \\
\hline 0 & 401 (45.9) & $184(51.1)$ & 217 (42.3) & 0.010 \\
\hline$\geq 1$ & $472(54.1)$ & 176 (48.9) & $296(57.7)$ & \\
\hline BP control & & & & 0.242 \\
\hline Good control & $287(32.9)$ & $110(30.6)$ & $177(34.5)$ & \\
\hline Poor control & $586(67.1)$ & $250(69.4)$ & $336(65.5)$ & \\
\hline
\end{tabular}

$\mathrm{BMI}$, body mass index; BP, blood pressure; CAD, coronary artery disease; COPD, chronic obstructive pulmonary disease; MI, myocardial infarction; NCMS, New Rural Cooperative Medical Scheme; UEMI, Urban Employees' Medical Insurance; URMI, Urban Residents' Medical Insurance; WC, waist circumference.

\section{DISCUSSION}

\section{Context of self-management and BP control}

The results of this study provide insights into the contextual self-management factors that impact BP control in China. A total of $67.1 \%$ of individuals with hypertension living in the community did not achieve recommended BP targets. Results are consistent with previous studies that suggest poor BP control is linked to a lower socioeconomic status. ${ }^{57-60}$ Individuals with UEMI health insurance and benefit packages that covered outpatient services had better BP control than those individuals enrolled with
NCMS (extremely limited outpatient care benefits for rural residents). ${ }^{61-63}$ Inadequate insurance and poor BP control is also supported by a US National Health and Nutrition Examination Survey. ${ }^{64}$

Results from this study also suggest that longer disease duration increases the odds of having poor BP control. This is consistent with a cross-sectional study in Hong Kong that suggested advanced age and longer duration of antihypertensive medication use was independently associated with poor BP control. ${ }^{65}$ The longer duration of hypertension may indicate poor adherence to

Table 2 Difference in self-management processes in community participants with hypertension

\begin{tabular}{|c|c|c|c|c|}
\hline & $\begin{array}{l}\text { Total } \\
(\mathrm{n}=873)\end{array}$ & $\begin{array}{l}\text { Men } \\
(n=360)\end{array}$ & $\begin{array}{l}\text { Women } \\
(n=513)\end{array}$ & \\
\hline & Mean (SD) & Mean (SD) & Mean (SD) & $P$ value \\
\hline Treatment management & $59.54(17.43)$ & $59.49(18.01)$ & $59.58(17.02)$ & 0.937 \\
\hline Diet management & $70.18(23.36)$ & $67.71(24.18)$ & $71.91(22.63)$ & 0.009 \\
\hline Physical exercise management & $60.80(32.69)$ & $59.63(33.21)$ & $61.62(32.33)$ & 0.377 \\
\hline Lifestyle management & $63.47(18.38)$ & $64.92(17.91)$ & $62.45(18.66)$ & 0.051 \\
\hline Risk factors management & $86.91(24.64)$ & $73.70(30.53)$ & $96.18(13.12)$ & $<0.001$ \\
\hline Total score & $65.58(13.22)$ & $63.61(14.28)$ & $66.96(12.25)$ & $<0.001$ \\
\hline No. of visiting $\mathrm{CHC}$ (per year), $\mathrm{n}(\%)$ & & & & 0.060 \\
\hline 0 & $322(36.9)$ & $146(40.6)$ & $176(34.3)$ & \\
\hline$\geq 1$ & $551(63.1)$ & $214(59.4)$ & $337(65.7)$ & \\
\hline No. of visiting hospital (per year), n (\%) & & & & 0.001 \\
\hline 0 & $653(74.8)$ & $290(80.6)$ & $363(70.8)$ & \\
\hline$\geq 1$ & $220(25.2)$ & 70 (19.4) & $150(29.2)$ & \\
\hline
\end{tabular}

$\mathrm{CHC}$, community health centres. 


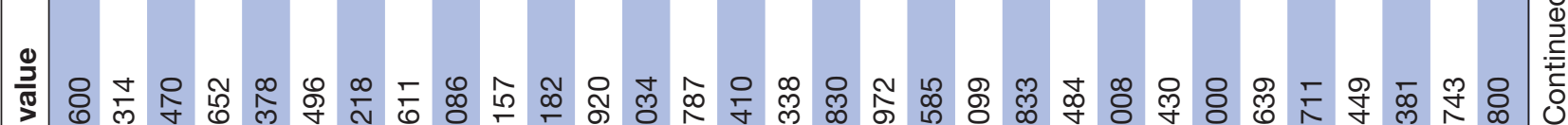

$\left.\begin{array}{l}2 \\ 0\end{array}\right)$

ㅇำ

$\begin{array}{r}i \\ \hline\end{array}$

广

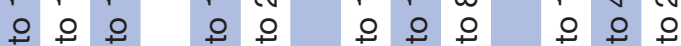

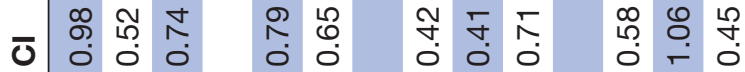

மำ ㄷำ

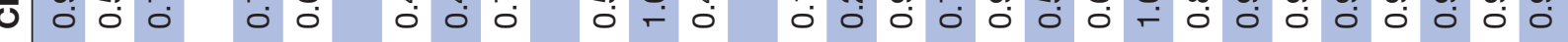

$\frac{m}{\frac{0}{6}}$

产

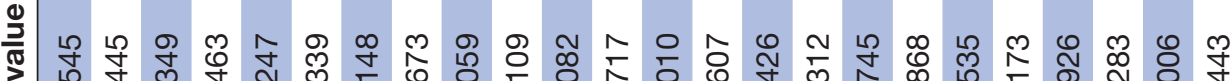

a

ர คิ

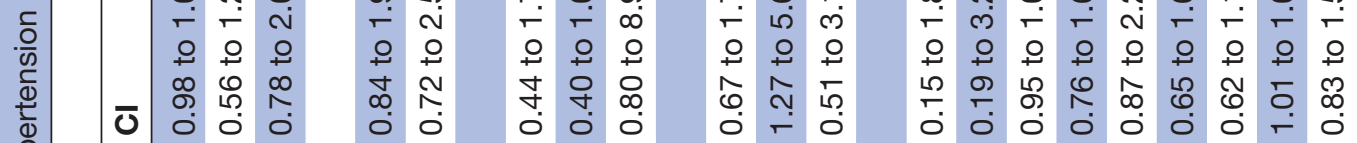

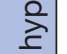

$\frac{\mathrm{O}}{\mathrm{d}}$

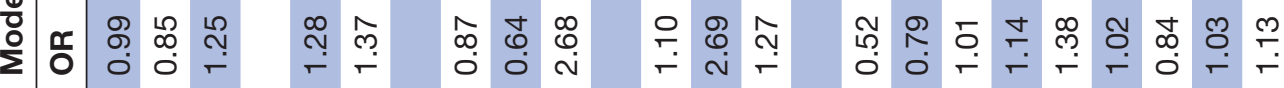

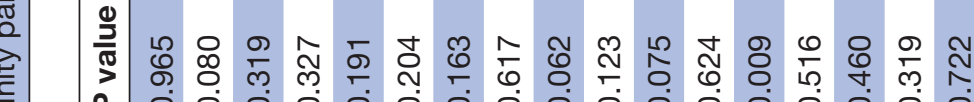

हो

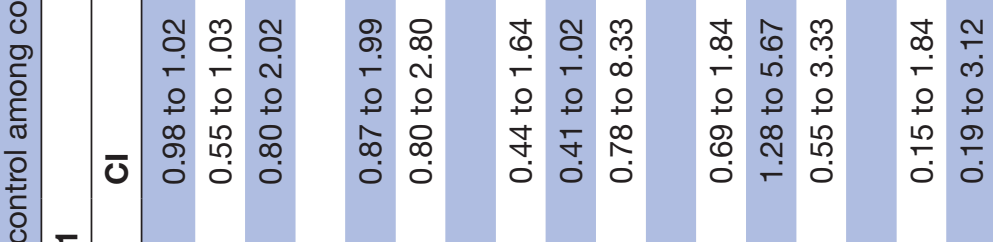

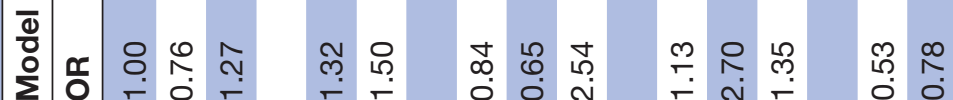

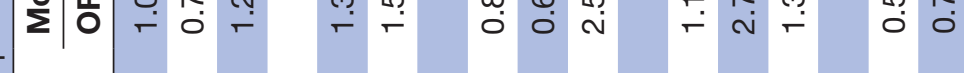

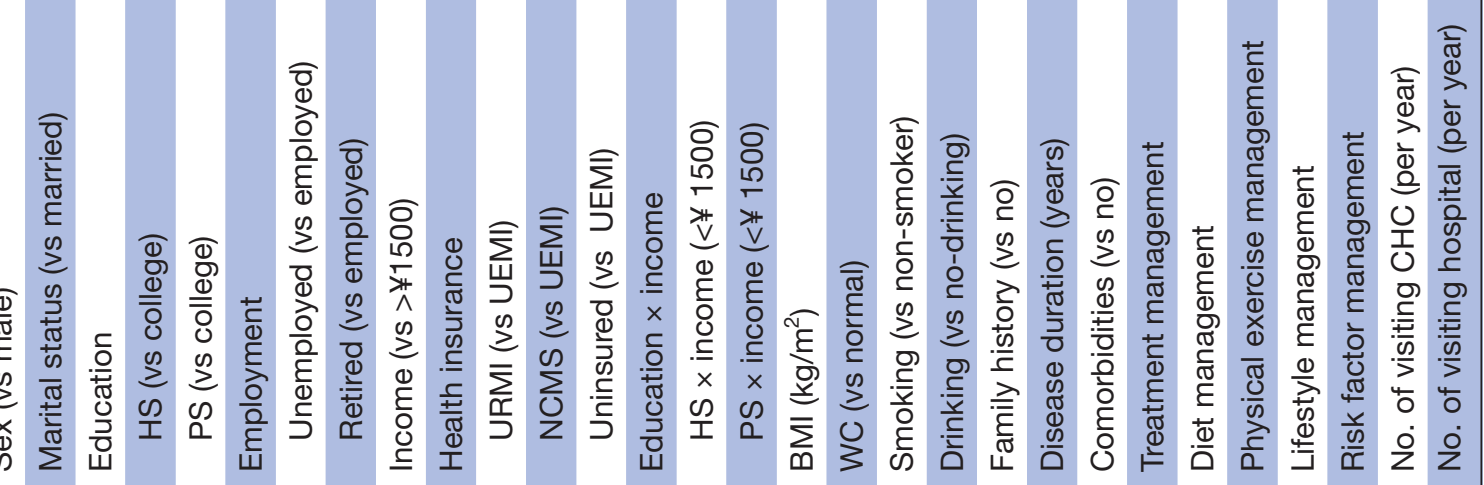




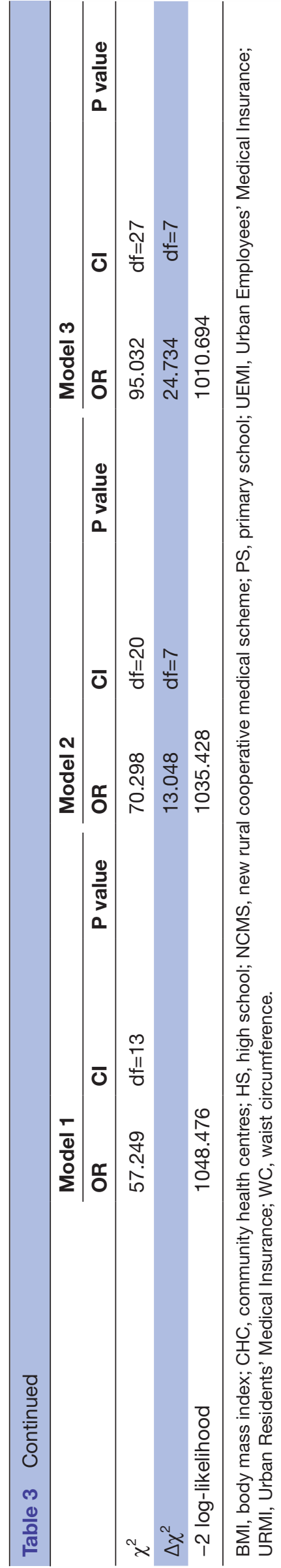

self-management practices. However, others reported good adherence and better BP control in elderly individuals (age $\geq 65$ years) with hypertension and a longer duration of antihypertensive medicine use. ${ }^{66}{ }^{67}$ In general, BP may be more difficult to control with increasing age. A cross-sectional study of outpatients in the USA reported that concomitant use of more than one antihypertensive medication increases with patient age (up to age 80 years, after which it then decreases); this may have an impact on the patient's willingness or ability to comply with the overall treatment regimens. ${ }^{68}$ More than half of the participants in this study had more than one comorbidity, which may have influenced participants' medication adherence.

Women in this study were significantly older and more likely to have more than one comorbidity (eg, arthritis and back and neck problems) compared with men. In addition to age, biological sex influences the development of comorbidities, ${ }^{69} 70$ such as hypertension after menopause. ${ }^{35}$ Comorbidities among women aged $60-79$ years with hypertension have been previously reported ${ }^{69}{ }^{70}$; they increase the complexities of care for women, ${ }^{71}$ and have been associated with poor self-care ability. ${ }^{71}$ Low income has not only been a predictor resulting in low adherence to medication regimens, ${ }^{72}$ it has also been a factor associated with the development of the comorbid disease ${ }^{73}$ More women in this study also lived alone with fewer supports compared with men. These findings may explain the more frequent unscheduled physician and CHC visits in women and provide important information for developing effective self-management interventions to improve BP control in China.

Individuals in this study with lower personal incomes were women; women who were older, lived alone, had lower education and were more likely to be unemployed. Level of education, hours of work, occupation and responsibility in caring for children has been conceptualised by others as gender related. ${ }^{74}$ Lower educated women compared with higher educated women and non-working women compared non-working men have been associated with poor BP control ${ }^{75} 76$; others report traditional sex differences in CVD risk factors are explained by feminine personality traits (ie, gender).$^{40}$ Neither sex nor gender affected BP control in this study, but it may be because we did not have a robust measure of gender. Gender has generally been defined across four dimensions including gender roles, gender identity, gender relationships and institutionalised gender. ${ }^{42}$ The important role gender may play in BP control requires further investigation, especially in a culture where boys are encouraged to pursue higher education and girls encouraged to work in the family home.

\section{Process of self-management and BP control}

This study is one of few to compare hypertensive self-management skills in treatment, diet, physical exercise, lifestyle and risk factors in China. Poor BP control was significantly associated with low self-management 
skills, especially in treatment management (eg, medication adherence, regularly scheduled doctors' visits and self-monitoring of BP). This is supported by the IFSMT theory, which purports successful BP control at the individual level is related to an individual's self-management skills and their involvement in the treatment and control of their condition. ${ }^{26} \mathrm{~A}$ lifelong adherence to prescribed antihypertensive medications, regular clinic visits and self-monitoring skills have assisted other individuals to control their BP. ${ }^{78}$ Non-adherence to treatment management is related to a higher risk of cardiovascular morbidity and mortality. ${ }^{79} 80$ Hypertension is an asymptomatic disease, most individuals with hypertension do not experience symptoms and may not feel it necessary to adhere to prescribed or suggested treatment regimens. ${ }^{81}$ Moreover, medication side effects may also deter individuals from adhering to prescribed or suggested treatment regimens, especially in the elderly Chinese. ${ }^{82}$ The perceived benefits of Chinese herbs may be more important than Western antihypertensive medications for elderly Chinese who tend to be less adherent with Western antihypertensive medications and believe Chinese herbs have fewer side effects. ${ }^{83}$ Integrating traditional practices into hypertension management regimens with frequent and careful monitoring of side effects and adjustment of medications may be warranted. Effectiveness and adherence to antihypertensive medication regimens depends on regularly scheduled visits to $\mathrm{CHC}^{25}$ Regular BP monitoring also reduces hypertension, ${ }^{19} 84$ suggesting home BP monitoring should have a primary role in long-term BP control in China.

The results of this study also show that women are more likely to have better skills in diet and risk factor management. The findings are consistent with those of Choi et $a l^{85}$ and Zhou et $a l^{86}$ who report that women with hypertension have higher diet management skills, especially related to the daily consumption of fresh vegetables and fruits, which are thought to be protective factors associated with better BP control. ${ }^{86}$

Diet and risk factor management were not significantly associated with BP control in this study and this may be because diet management (eg, balanced diet and salt/ sodium control) is difficult for participants to conceptualise. This requires exploration in a future study.

Limitations: There are several limitations to the study. First, this study is cross-sectional and results may be subject to a non-response bias. ${ }^{55}$ There could be other unobserved confounding factors we have neither considered nor controlled. However, recruiting a large number of individuals with hypertension across four areas of China attempted to minimise this bias. Second, many of the context and process variables were self-reported, increasing the potential for a response bias. Third, the self-management for patients with hypertension scale has not been widely used and need further psychometric testing. Lastly, a more robust measure of gender needs to be incorporated into future research. The strengths of the study include the use of the IFSMT and the incorporation of sex and gender-based lens to guide the data analyses and interpretation.

\section{CONCLUSION}

This is one of few studies using IFSMT theory to assess how context and process variables influence self-management and BP in individuals with hypertension. Context variables related to longer disease duration and NCMS health insurance (inadequate outpatient care benefits for rural residents) were associated with poor control of hypertension in China. Lower cost sharing of outpatient care, increasing access to preventive care and improving accessibility to medications and self-management strategies for NCMS enrollees should be considered by Chinese healthcare policy-makers. Moreover, sex and gender-related factors including strategies to improve self-management skills and provide social supports need to be investigated in future randomised controlled trials.

Acknowledgements We thank all participants involved in the research. We are grateful to the nurses, doctors and health care providers in the community health centers for their efforts in coordination of the fieldwork. We thank Ying Zhang, Yue Ma and Yiping Nan for their assistance with data collection.

Contributors XL was a major contributor in project administration, research design, organising the fieldwork, giving advice on the manuscript writing and supervision. $Z Q$ and MP were major contributors in data analysis, manuscript writing and revision. ZQ, FL, XW and JL were involved in community nursing training in blood pressure measurement, providing patient-centred questionnaire instructions, collecting data and inputting results into the database. ZQ, MP, YZ and DW analysed and interpreted all patient data. All authors have read and approved the final manuscript.

Funding This work was supported by China Medical Board, Grant Number (11-085).

Competing interests None declared.

Patient consent for publication Obtained.

Ethics approval This study was approved by the Ethics Committee of Xi'an Jiaotong University Health Science Center (Approval No. 2014-008).

Provenance and peer review Not commissioned; externally peer reviewed. Data sharing statement № additional data are available.

Open access This is an open access article distributed in accordance with the Creative Commons Attribution Non Commercial (CC BY-NC 4.0) license, which permits others to distribute, remix, adapt, build upon this work non-commercially, and license their derivative works on different terms, provided the original work is properly cited, appropriate credit is given, any changes made indicated, and the use is non-commercial. See: http://creativecommons.org/licenses/by-nc/4.0/.

\section{REFERENCES}

1. NCD Risk Factor Collaboration (NCD-RisC). Worldwide trends in blood pressure from 1975 to 2015: a pooled analysis of 1479 population-based measurement studies with $19 \cdot 1$ million participants. Lancet 2017;389:37-55.

2. Chow CK, Teo KK, Rangarajan S, et al. Prevalence, awareness, treatment, and control of hypertension in rural and urban communities in high-, middle-, and low-income countries. JAMA 2013;310:959-68.

3. Roger VL, Go AS, Lloyd-Jones DM, et al. Executive summary: heart disease and stroke statistics--2012 update: a report from the American Heart Association. Circulation 2012;125:188-97.

4. Liu L. Cardiovascular diseases in China. Biochem Cell Biol 2007;85:157-63.

5. He J, Gu D, Wu X, et al. Major causes of death among men and women in China. N Engl J Med 2005;353:1124-34. 
6. Reynolds K, Gu D, Muntner P, et al. Geographic variations in the prevalence, awareness, treatment and control of hypertension in China. J Hypertens 2003;21:1273-81.

7. Wang Z, Chen Z, Zhang L, et al. Status of Hypertension in China: Results from the China Hypertension Survey, 2012-2015. Circulation 2018.

8. Lu J, Lu Y, Wang X, et al. Prevalence, awareness, treatment, and control of hypertension in China: data from 1.7 million adults in a population-based screening study (China PEACE Million Persons Project). Lancet 2017;390:2549-58.

9. Yang G, Wang Y, Zeng Y, et al. Rapid health transition in China, 1990-2010: findings from the Global Burden of Disease Study 2010. The Lancet 2013;381:1987-2015.

10. Liu LS. [2010 Chinese guidelines for the management of hypertension]. Am J Hypertens 2012;25:271.

11. Liu L, Wang D, Wong KS, et al. Stroke and stroke care in China: huge burden, significant workload, and a national priority. Stroke 2011;42:3651-4.

12. Blood pressure, cholesterol, and stroke in eastern Asia. Eastern Stroke and Coronary Heart Disease Collaborative Research Group. Lancet 1998;352:1801-7.

13. Collins R, Peto R, MacMahon S, et al. Blood pressure, stroke, and coronary heart disease. Part 2, Short-term reductions in blood pressure: overview of randomised drug trials in their epidemiological context. Lancet 1990;335:827-38.

14. Moran AE, Odden MC, Thanataveerat A, et al. Cost-effectiveness of hypertension therapy according to 2014 guidelines. N Engl J Med 2015;372:447-55.

15. Penaloza-Ramos MC, Jowett S, Mant J, et al. Cost-effectiveness of self-management of blood pressure in hypertensive patients over 70 years with suboptimal control and established cardiovascular disease or additional cardiovascular risk diseases (TASMIN-SR). Eur J Prev Cardiol 2016;23:902-12.

16. Tsai JC, Yang HY, Wang WH, et al. The beneficial effect of regular endurance exercise training on blood pressure and quality of life in patients with hypertension. Clin Exp Hypertens 2004;26:255-65.

17. Wolff M, Sundquist K, Larsson Lönn S, et al. Impact of yoga on blood pressure and quality of life in patients with hypertension - a controlled trial in primary care, matched for systolic blood pressure. BMC Cardiovasc Disord 2013;13:111

18. Hesketh T, Zhou X. Hypertension in China: the gap between policy and practice. Lancet 2017;390:2529-30.

19. McManus RJ, Mant J, Haque MS, et al. Effect of self-monitoring and medication self-titration on systolic blood pressure in hypertensive patients at high risk of cardiovascular disease: the TASMIN-SR randomized clinical trial. JAMA 2014;312:799-808.

20. Tucker KL, Sheppard JP, Stevens R, et al. Self-monitoring of blood pressure in hypertension: a systematic review and individual patient data meta-analysis. PLoS Med 2017;14:e1002389.

21. Bosworth HB, Olsen MK, Grubber JM, et al. Two self-management interventions to improve hypertension control: a randomized trial. Ann Intern Med 2009;151:687-95.

22. Magid DJ, Farmer SA. Hypertension self-management. Circulation: Cardiovascular Quality and Outcomes 2014;7:205-6.

23. Huang YC, Garcia AA. Culturally-tailored interventions for chronic disease self-management among Chinese Americans: a systematic review. Ethn Health 2018;20.

24. Fu D, Fu H, McGowan P, et al. Implementation and quantitative evaluation of chronic disease self-management programme in Shanghai, China: randomized controlled trial. Bull World Health Organ 2003;81:174-82.

25. Gu J, Zhang XJ, Wang TH, et al. Hypertension knowledge, awareness, and self-management behaviors affect hypertension control: a community-based study in Xuhui District, Shanghai, China. Cardiology 2014;127:96-104.

26. Ryan P, Sawin KJ. The individual and family self-management theory: background and perspectives on context, process, and outcomes. Nurs Outlook 2009;57:217-25.

27. Bodenheimer T, Lorig K, Holman $\mathrm{H}$, et al. Patient self-management of chronic disease in primary care. JAMA 2002;288:2469-75.

28. Bodenheimer T, Wagner EH, Grumbach K. Improving primary care for patients with chronic illness. JAMA 2002;288:1775-9.

29. Halme L, Vesalainen R, Kaaja M, et al. Self-monitoring of blood pressure promotes achievement of blood pressure target in primary health care. Am J Hypertens 2005;18:1415-20.

30. McManus RJ, Mant J, Roalfe A, et al. Targets and self monitoring in hypertension: randomised controlled trial and cost effectiveness analysis. BMJ 2005;331:493.

31. Grady PA, Gough LL. Self-management: a comprehensive approach to management of chronic conditions. Am J Public Health 2014;104:e25-31.
32. Abramson BL, Melvin RG. Cardiovascular risk in women: focus on hypertension. Can J Cardiol 2014;30:553-9.

33. Ong KL, Tso AW, Lam KS, et al. Gender difference in blood pressure control and cardiovascular risk factors in Americans with diagnosed hypertension. Hypertension 2008;51:1142-8.

34. Gu Q, Burt VL, Paulose-Ram R, et al. Gender differences in hypertension treatment, drug utilization patterns, and blood pressure control among US adults with hypertension: data from the National Health and Nutrition Examination Survey 1999-2004. Am J Hypertens 2008;21:789-98.

35. Everett B, Zajacova A. Gender differences in hypertension and hypertension awareness among young adults. Biodemography Soc Biol 2015;61:1-17.

36. Haskell WL, Lee IM, Pate RR, et al. Physical activity and public health: updated recommendation for adults from the American College of Sports Medicine and the American Heart Association. Circulation 2007;116:1081.

37. Gueyffier F, Boutitie F, Boissel JP, et al. Effect of antihypertensive drug treatment on cardiovascular outcomes in women and men. A meta-analysis of individual patient data from randomized, controlled trials. The INDANA Investigators. Ann Intern Med 1997;126:761-7.

38. Gahagan J, Gray K, Whynacht A. Sex and gender matter in health research: addressing health inequities in health research reporting. Int J Equity Health 2015;14:12.

39. Daugherty SL, Masoudi FA, Ellis JL, et al. Age-dependent gender differences in hypertension management. $J$ Hypertens 2011;29:1005-11.

40. Pelletier R, Ditto B, Pilote L. A composite measure of gender and its association with risk factors in patients with premature acute coronary syndrome. Psychosom Med 2015;77:517-26.

41. Johnson JL, Greaves L, Repta R. Better science with sex and gender: facilitating the use of a sex and gender-based analysis in health research. Int J Equity Health 2009;8:14.

42. How to integrate sex and gender into research. http://www.cihr-irsc. gc.ca/e/50836.html (Accessed 23 Jul 2018).

43. National Health and Family Planning Commission of the People's Republic of China. The Notice of Ministry of Health General Office of the Announcement of the List of National Model Community Health Care Centers in 2011. 2011. (In Chinese) http://www.nhfpc.gov.cn/ zwgkzt/wsbysj/201112/53666.shtml (Accessed 24 May 2018).

44. National Health and Family Planning Commission of the People's Republic of China. The Notice of Ministry of Health General Office of the Announcement of the List of National Model Community Health Care Centers in 2012. 2012. (In Chinese) http://www.nhfpc.gov.cn/ zwgkzt/wsbysj/201211/56380.shtml (Accessed 24 May 2018).

45. National Health Commission of the People's Republic of China. The Notice of the General Office of the National Health and Family Planning Commission on the Announcement of the List of National Model Community Health Care Centers in 2013. 2013. (In Chinese) http://www.nhfpc.gov.cn/jws/s3581r/201310/efaefdd8d2d147fb8781 d6bef5ecad53.shtml (Accessed 24 May 2018).

46. Yu J, Li J, Huang X. The Beijing version of the Montreal Cognitive Assessment as a brief screening tool for mild cognitive impairment: a community-based study. BMC Psychiatry 2012;12:156.

47. The Central People's Government of the People's Republic of China. Decision of the Standing Committee of the National People's Congress Regarding the Amendment to the Individual Income Tax Law of the People's Republic of China. 2011. (In Chinese) http:// www.gov.cn/flfg/2011-07/01/content_1897307.htm (Accessed 24 May 2018)

48. Zhou BF. Cooperative Meta-Analysis Group of the Working Group on Obesity in China. Predictive values of body mass index and waist circumference for risk factors of certain related diseases in Chinese adults--study on optimal cut-off points of body mass index and waist circumference in Chinese adults. Biomed Environ Sci 2002;15:83-96.

49. Zhou BF. Effect of body mass index on all-cause mortality and incidence of cardiovascular diseases--report for meta-analysis of prospective studies open optimal cut-off points of body mass index in Chinese adults. Biomed Environ Sci 2002;15:245-52.

50. Chen C, Lu FC. Department of Disease Control Ministry of Health, PR China. The guidelines for prevention and control of overweight and obesity in Chinese adults. Biomed Environ Sci 2004;17:1-36.

51. Alberti KG, Zimmet P, Shaw J. International Diabetes Federation: a consensus on Type 2 diabetes prevention. Diabet Med 2007;24:451-63.

52. National Institute for Health and Care Excellence. BMI: preventing ill health and premature death in black, Asian and other minority ethnic groups. 2013 https://www.nice.org.uk/guidance/ph46/chapter/1Recommendations (Accessed 23 Jul 2018).

53. Liu N, Zhang J, Yu X, et al. Development and testing of reliability and validity of self-management scale for patients with hypertension 高血 
压病人自我管理量表的研制与信效度检验. Chinese Nursing Research 护理研究: 中旬版 2015;29:1764-7.

54. Liu L. Chinese guidelines for the management of hypertension. Zhonghua xin xue guan bing za zhi 2010;39:579-615.

55. Sedgwick P. Cross sectional studies: advantages and disadvantages. BMJ: British Medical Journal 2014:348.

56. Palmer PB, O'Connell DG. Regression analysis for prediction: understanding the process. Cardiopulm Phys Ther J 2009;20:23-6.

57. Abegaz TM, Shehab A, Gebreyohannes EA, et al. Nonadherence to antihypertensive drugs: A systematic review and meta-analysis. Medicine 2017;96:e5641.

58. Paulsen MS, Andersen M, Munck AP, et al. Socio-economic status influences blood pressure control despite equal access to care. Fam Pract 2012;29:503-10.

59. Leng B, Jin Y, Li G, et al. Socioeconomic status and hypertension: a meta-analysis. J Hypertens 2015;33:221-9.

60. Moser KA, Agrawal S, Davey Smith G, et al. Socio-demographic inequalities in the prevalence, diagnosis and management of hypertension in India: analysis of nationally-representative survey data. PLoS One 2014;9:e86043.

61. Liu GG, Vortherms SA, Hong X. China's Health Reform Update. Annu Rev Public Health 2017:38:431-48.

62. Feng $\mathrm{XL}$, Pang $\mathrm{M}$, Beard J. Health system strengthening and hypertension awareness, treatment and control: data from the China Health and Retirement Longitudinal Study. Bull World Health Organ 2014;92:29-41.

63. Liu J, Shi L, Meng Q, et al. Income-related inequality in health insurance coverage: analysis of China Health and Nutrition Survey of 2006 and 2009. Int J Equity Health 2012;11:42.

64. Duru OK, Vargas RB, Kermah D, et al. Health insurance status and hypertension monitoring and control in the United States. Am J Hypertens 2007;20:348-53.

65. Munger MA, Van Tassell BW, LaFleur J. Medication nonadherence: an unrecognized cardiovascular risk factor. MedGenMed 2007;9:58.

66. Wang W, Lau Y, Loo A, et al. Medication adherence and its associated factors among Chinese community-dwelling older adults with hypertension. Heart Lung 2014;43:278-83.

67. Yue Z, Bin W, Weilin Q, et al. Effect of medication adherence on blood pressure control and risk factors for antihypertensive medication adherence. J Eval Clin Pract 2015;21:166-72.

68. Borzecki AM, Glickman ME, Kader B, et al. The effect of age on hypertension control and management. Am J Hypertens 2006;19:520-7.

69. Violán C, Foguet-Boreu Q, Roso-Llorach A, et al. Burden of multimorbidity, socioeconomic status and use of health services across stages of life in urban areas: a cross-sectional study. BMC Public Health 2014:14:530.

70. Noh J, Kim HC, Shin A, et al. Prevalence of Comorbidity among People with Hypertension: The Korea National Health and Nutrition Examination Survey 2007-2013. Korean Circ J 2016;46:672-80.
71. Chriss PM, Sheposh J, Carlson B, et al. Predictors of successful heart failure self-care maintenance in the first three months after hospitalization. Heart Lung 2004;33:345-53.

72. Ma C. A cross-sectional survey of medication adherence and associated factors for rural patients with hypertension. Appl Nurs Res 2016;31:94-9.

73. Li YT, Wang HH, Liu KQ, et al. Medication adherence and blood pressure control among hypertensive patients with coexisting longterm conditions in primary care settings: a cross-sectional analysis. Medicine 2016;95:e3572.

74. Smith PM, Koehoorn M. Measuring gender when you don't have a gender measure: constructing a gender index using survey data. Int $J$ Equity Health 2016;15:82.

75. Rahman M, Williams G, Al Mamun A. Gender differences in hypertension awareness, antihypertensive use and blood pressure control in Bangladeshi adults: findings from a national crosssectional survey. J Health Popul Nutr 2017;36:23.

76. Chu SH, Baek JW, Kim ES, et al. Gender differences in hypertension control among older korean adults: Korean social life, health, and aging project. J Prev Med Public Health 2015;48:38.

77. Chobanian AV, Bakris GL, Black HR, et al. Seventh report of the Joint National Committee on prevention, detection, evaluation, and treatment of high blood pressure. Hypertension 2003;42:1206-52.

78. Nguyen QC, Waddell EN, Thomas JC, et al. Awareness, treatment, and control of hypertension and hypercholesterolemia among insured residents of New York City, 2004. Prev Chronic Dis 2011;8.

79. Wogen J, Frech F. Patient adherence with hypertension medication. $J$ Manag Care Pharm 2004;10:90-1.

80. Morisky DE, Ang A, Krousel-Wood M, et al. Predictive validity of a medication adherence measure in an outpatient setting. $J$ Clin Hypertens 2008:10:348-54.

81. King-Shier KM, Singh S, Khan NA, et al. Ethno-Cultural considerations in cardiac patients' medication adherence. Clin Nurs Res 2017:26:576-91.

82. Hsu YH, Mao CL, Wey M. Antihypertensive medication adherence among elderly Chinese Americans. J Transcult Nurs 2010;21:297-305.

83. Li WW, Stewart AL, Stotts N, et al. Cultural factors associated with antihypertensive medication adherence in Chinese immigrants. $J$ Cardiovasc Nurs 2006;21:354-62.

84. Stergiou GS, Kollias A, Zeniodi M, et al. Home blood pressure monitoring: primary role in hypertension management. Curr Hypertens Rep 2014;16:462.

85. Choi HM, Kim HC, Kang DR. Sex differences in hypertension prevalence and control: analysis of the 2010-2014 Korea National Health and Nutrition Examination Survey. PLoS One 2017;12:e0178334.

86. Zhou H, Wang K, Zhou X, et al. Prevalence and gender-specific influencing factors of hypertension among Chinese Adults: a crosssectional survey study in Nanchang, China. Int J Environ Res Public Health 2018;15:382. 